\title{
Informal Practices of Municipal Governance in the Context of Social and Demographic Development of Rural Areas
}

\author{
Oleg Bykhtin \\ Department of Social Technologies and Public Service \\ Belgorod State National Research University \\ Belgorod, Russia \\ bykhtin@bsu.edu.ru \\ Galina Gaidukova \\ Department of Social Technologies and Public Service \\ Belgorod State National Research University \\ Belgorod, Russia \\ g_gaidukova@bsu.edu.ru
}

\author{
Svetlana Vangorodskaya \\ Department of Social Technologies and Public Service \\ Belgorod State National Research University \\ Belgorod, Russia \\ vangorodskaya@bsu.edu.ru \\ Olga Yurkova \\ Department of Social Technologies and Public Service \\ Belgorod State National Research University \\ Belgorod, Russia \\ yurkova@bsu.edu.ru
}

\begin{abstract}
The key purpose of the article is contained in the analysis of informal practices in municipal management in terms of socio-economic development of rural areas on the basis of the analysis of available empirical data. The properties of informal practices in the context of the socio-demographic development of rural areas were identified, and an attempt was made to explain the consequences of their application for the municipalities of Russia. It is proved that in municipal management in the conditions of socio-demographic development of rural areas, there are real prerequisites for their spread: the presence of a short social distance between participants; the inclusion of the population in the management process, which cannot always be foreseen and fully regulated; the traditions of informal communications in the local community, which are transferred to the system of municipal management of rural development. Based on the materials of an empirical study, typical informal practices applied at the level of rural settlements in the context of socio-demographic development are systematized. Within the framework of the article, theoretical and practical studies of the authors of the research team in the field of institutionalization of informal practices in the context of the socio-demographic development of rural areas are presented. The main data of sociological research, conducted among municipal officials and the population in rural areas of the Belgorod region, as well as experts in the field of state and municipal management.
\end{abstract}

Keywords-municipal government, informal practices, rural areas, lobbying, socio-demographic development, practices, social norms.

\section{INTRODUCTION}

To date, the extent of informal practices in professional work of municipal employees is quite large. You can talk about the fact that informal practices in terms of socioeconomic development of rural areas and will continue to be used in municipal management system, and their impact on the situation will grow by virtue of certain factors. The radical transformation of the system of municipal governance in the post-Soviet period and administrative reforms of recent years have not been able to significantly reduce the role of informal practices, we can assume that their importance as the tradition of domestic control, at least, continue in the medium-term development.

It should be noted that municipal governance in the context of socio-demographic development of rural areas is characterized by the use, along with formal, informal practices of making managerial decisions, which are sustainable, reproducible activities of actors-actors aimed at transforming formal norms, performing compensating functions. Often, informal practices in municipal governance in the context of socio-demographic development of rural areas can represent a kind of "standard working procedures" that regulate the activities of various subjects of management, which are largely determined by informal practice.

The formation of scientific concepts of municipal management evolved significantly influenced by beliefs and scientific positions M. Weber - the concept of minimizing the power was put in the core of the next theoretical research [1].

In domestic science interest in the local self-government was restored in the period of democratization and decentralization of society in the early 1990s, and, of course, related to the implementation of the municipal reform. However, for a long time, local self-government was influenced only by legal sciences and problems (I.V. Vydrin, V.A. Yasyunas, etc.) [2, 3] and, sometimes, by economic problems, such as problems of inter-budgetary relations (In A. Gnevko, A. E. Kogut and others) [4].

Later, in the works of G.V. Atamanchuk, V.N. Ivanova, N.I. Lapin, V.I. Patrushev and other authors began to form a view of municipal government as a specific area of social management in general, which required an analysis of the specifics of management practices, especially in the context of reforms $[5,6,7]$. In particular, T.G. Golubeva attempted to analyze the differences in the theoretical justification of the reform of municipal governance and the practical implementation of modernization measures, which, in her opinion, are an obstacle to improving the system of local selfgovernment in Russia [8]. 
Basic for understanding "practices" are the scientific developments of P. Bourdieu and N. Fligstein about the social field, who considered practices through the structures and institutions that implement them $[9,10]$, as well as P. Berger and T. Luckmann, who studied practices within the framework of the theory construction of social reality [11].

The informal practices of the domestic political elite are studied in the works of A.B. Daugavet, J.T. Toshchenko and others [12,13]. The study of the specifics of informal practices at the regional level was carried out in the works of A.K. Magomedov [14]. In particular, he focuses on the problems of informal social networks, patron-client relations, lobbying the interests of corporate business. To research the topic, it is of interest to analyze corruption practices in the regions of Russia and anti-corruption policy in the works of S.S. Sulakshina, A.V. Ponedelkov and other researchers $[15,16]$.

Of particular importance for the study have papers on social technologies and social and technological culture officials (V.P. Babintsev, L.Y. Dyatchenko, R.I. Sarik) $[17,18]$.

Directly in terms of socio-economic development of rural areas, informal practices have not been considered.

\section{MethodOLOGY}

The methodological basis of the research was formed by scientific statements and conclusions, which were reflected in the fundamental works of 3. Bauman, P. Berger, the practice-oriented approach of $\mathrm{M}$. Weber, considering practices within the framework of the behavioral approach $[19,11,20]$. The study was carried out on the basis of institutionalization analysis, which was reflected in the works of D. North, G. Helmke and S. Levitski, which allows interpreting local government as an institution that combines a set of formal and informal practices [21, 22]. The methodological approach of T. Parsons involves considering the phenomenon of informal practices through the prism of the category of social action [23]. When studying informal practices, the methodology of structural and functional analysis was also applied (E. Durkheim, R. Merton) [24,25].

The empirical basis of the study was the results of the sociological study "The Application of Informal Practices in the Bodies of Municipal Government" conducted by the staff of the Institute of Economics and Management of the National Research University "BelSU" in 2015 in the Belgorod Region $(\mathrm{N}=800)$.

\section{MAIN PART}

T M. Weber, speaking about practices, started from the concept of "action", which assumes a subjective attitude to various objects [1].

In the works of E. Giddens it is noted: "In their activity and through this activity, agents reproduce the conditions that make it possible" [21].

In the study, in relation to the system of municipal management of practices, we determine the actions of the subjects of municipal government, ensuring the solution of the problems of the residents of the local community and its stable reproduction. Here, by the local community is defined as "a community of people living in a certain territory and united by common interests in dealing with issues of life through the use and development of local material and social resources on the principles of self-government" [29].
In the system of municipal government in the context of the socio-demographic development of rural areas, formal and informal practices are applied. Based on the analysis of the investigated cases, it can be hypothesized that at the level of formal procedures, the activities of self-government bodies of practice in the conditions of socio-demographic development of rural areas generally comply with the legislation: the election procedure, the structure of self-government bodies, the necessary documents are available in the manner specified by law. However, the meaning inherent in the concept of local self-government does not at all correspond to the observed realities, the participation of the population in the management of the community is reduced to a minimum.

Informal practices are the opposite of formal ones. The basis of the economic interpretation of informal practices is the neoinstitutional methodology presented in the studies of Western and Russian scientists. For example, K. Polanyi, as a source of informal practices, analyzes three principles of the functioning of the household: reciprocity, that is, the method of transferring benefits, which consists in their ritualized donation, redistribution based on the concentration of resources in a single center, and household [30,31]. V.V. Radaev notes that informal relationships, requirements and restrictions can arise in the "gray zone", that is, where the interaction between government and business can deformalize rules and norms, which is directly the basis for informal practices [32].

The most common approach to the study of informal relationships and practices is an institutional approach, under which they regarded as a mandatory element of the functioning of any social institution, which can not only operate on the basis of a strict set of rules. This approach allows us to clarify ideas about the role of informal practices in the process of institutionalization of the system of municipal government. Most often, this problem is treated in the following manner: the formal (legal) practice complemented by regulatory and ritual, and in the management of integrated rituals (sometimes - rites), honored traditions. At first glance, this understanding is based on the existing interpretation of the phenomena of the Institute and institutionalization. But, if we proceed from the fact that the legal and ritual practices - is a special case of formal practices, adjustments should be made in a common presentation. Informal practices in this context - is a non-institutionalized action. Of course, they can complement the formal practice of the first and second levels, but, in essence, means of negation, indicating the ineffectiveness of formal institutions.

It should be noted that four aspects highlighted in sociology when characterizing informal practices are more important when we consider local self-government. First, informal institutional aspect here has a distinct character, as the local government is a special social institution, which is dual in nature. This is due to the fact that, on the one hand, local self-government is associated with state selfgovernment, which has a completely formalized nature, and on the other hand, it is associated with the public private life of people, their inclusion in the management system, presupposes the initiative and participation of people, based on customs and traditions, which cannot be fully formalized and regulated.

Secondly, a place for informal control at the local government level is implied from the outset. If at the state level the importance placed on administrative regulations, at the municipal level, it is assumed that the local community 
should monitor the activities of local authorities in dealing with the issue of local importance.

Third, informal communication at the level of local government and municipal management system itself are close in nature, due to the limited space in the form of the boundaries of the municipality, are student-centered and nature of informal relations play an important role here.

Fourth, the manifestation of an informal system of municipal management due to the proximity of the subject and object of management, as well as in resource-limited settings where the formal rules do not allow to solve local issues at the appropriate level.

Taking into account the considered position, we believe it is possible in relation to the municipal government to determine the informal practices in municipal management in terms of socio-economic development of rural areas as a usergenerated patterns of behavior in the exercise of the head of administrative action for the implementation of choice alternatives that do not rely on the scientific validity of and adherence to the strategic orientations of development municipality, but on the own interests of individuals. Based on the analysis of the study of literature, it is possible to identify a number of properties that become informal practices in terms of socio-economic development of rural areas acquire a number of properties.

Selectivity. In all analyzed types of interactions, it is a kind of universal rule and covers a variety of management functions. Most often destructive potential manifests itself as a result of achievement of personal goals and to benefit directly the subject of municipal management. In this context, it becomes necessary to gradually eliminate and minimize destructive informal practices and use the potential of constructive ones. However, there is a factor complicating the implementation of this process, namely - the presence in most practices simultaneous destructive and constructive building except uniquely destructive and criminal (corruption, clientalism etc.).

In this case, the central concept here is the situation in which the definitions of informal practices, that is, there are certain conditions that characterize the destructive and constructive aspects of the practice, depending not only on their internal state, but also on the external situation in which they are used in the system municipal government. The implementation of the classical situational approach in the system of municipal management for the development of general conditions for various situations acts to determine the most effective management methods in each specific case. However, when assessing the relationship of constructive and destructive potential in an informal practice is necessary to rely on all the conditions and circumstances under which it is implemented and enforced.

Normality. As local self-government is institutionalized, the corresponding interactions in making managerial decisions form a set of certain ethical norms that affect all participants in the process or fit into an already existing system of ethical prescriptions and restrictions. If the law cannot act as an effective norm in this case, then a large-scale ethical system replaces it, and allows it to perform the same functions of forming patterns of behavior, legitimizing expectations, creating a basis for social control and sanctions. The system can be as simple as a generalization of certain provisions of the common sense, but it is usually a combination of bureaucratic norms of ethics (behavioral norms dictated hierarchical), specific standards that characterize this particular structure and ethics of closed groups. Another form of the application of informal practices in management decisions in favor of public and private syncretism.

Syncretism of the public and the private. To the extent that the process of municipal government is a legacy of archaic forms of social life, it inevitably tends to such syncretism.

Implicitness. In the system of municipal government in terms of socio-economic development of rural areas forms administrative interactions often rely primarily on implicit, tacit knowledge: the rules and regulations, legitimate expectations often are not verbalized, but implied.

However, it should be noted that informal practices in the context of socio-demographic development of rural areas have not only negative, but sometimes positive consequences. Informal practices in some cases can replace formal ones where they cannot function successfully. They take into account the characteristics of a person as a subject of managerial relations, and formal practices unify the entire management process and do not take into account personality characteristics. If formal practices do not imply a trusting aspect, then informal ones allow to create this atmosphere and stabilize the local community.

Among the positive functions, the following should be highlighted:

- Compensatory - informal practices make up for the shortcomings of formal practices. An attempt is being made to compensate for the lack of resources. Informal mechanisms and practices for making management decisions are most often used in conditions of limited resources;

- Mobilization - informal practices mobilize the personal resource of management. In most cases, informal practices are focused on using the potential of the social capital of the participants in the interaction. By social capital in this case, we mean "a resource that actors receive through special social structures and then use for their own purposes; this is produced by changes in the relationship between actors" [34];

- Adaptive - informal practices simplify and speed up the decision-making process;

- Differentiating - overcomes the costs of universalism, which is inevitable in formalized actions.

Among the negative functions that informal practices perform in municipal administration in the context of the social and demographic development of rural areas, it should be noted:

- disintegration - informal practices stimulate social anomie, lowering the importance of values and norms in management;

- corruption - informal practices initiate and provoke corrupt relations and connections, artificially creating situations in which an act of corruption is perceived as the only reasonable way to solve a problem.

In this regard, it is interesting to consider a sociological study conducted by the staff of the National Research University "Belgorod State University" in 2018, the purpose of which was to study the perception of informal practices by direct participants in municipal government in the Belgorod region $(\mathrm{N}=800)$. According to a study at the community level underestimation of the existing formal rules and regulations and, as a consequence, the statement as a very natural style of behavior of non-compliance is maintained for a number of features of its self-organization. The expert distribution of answers showed that the absolute majority of scientists and university professors point to the presence of such practices in the system of municipal government $83.3 \%$ (of the total number of those who answered this question positively). At the 
same time, almost half of the experts whose professional activities are related to state or municipal administration found it difficult to answer the question posed in the questionnaire. Among the municipal employees the answers were distributed as follows. It is significant that only $12 \%$ disagree with the existing point of view versus $22 \%$ of those who found it difficult or did not answer the question. At the same time, it should be noted that respondents over the age of 50 refused to answer the question. The presence of informal practices in the system of municipal government is recognized mainly by respondents aged 30-39 years old and with more than 10 years of work experience $(36.8 \%)$.

It is important to note the fact that municipal officials understand informal practices as those that go beyond the legal norms or are simply not provided for by them.

Of course, the development and management decisionmaking in municipal service rather strictly regulated and bureaucratic, by virtue of which the person receiving the administrative decision, in an attempt to speed up the processrefer to the informal practices. However, among the experts, this answer option did not deserve due attention, only $16 \%$ think so.

Speaking about the reasons for the spread of informal practices, municipal employees $(34 \%)$ and experts $(53.3 \%)$ agreed that they allow you to neutralize the imperfection of normative-legal acts. In this case, the use of informal practices gives the formal institutions of municipal governance the flexibility necessary for making management decisions.

This distribution of answers confirms that the regulatory legal framework of local self-government has significant shortcomings, which allows most officials to use informal practices in their professional activities. Note that half of the experts pointed to this fact $(53.3 \%)$. This reason also leads to the following - the bureaucratization of the municipal government system. Often, in order to speed up the decisionmaking process and bypass procedures, which are often only formal and unnecessary, officials resort to informal practices.

Assessing the impact of informal practices on the activities of municipal administrations, experts and officials note more negative than positive (46.7\%, respectively). However, according to experts, officials assess the appeal to informal practices rather positively than negatively $(46.7 \%$ and $50 \%$, respectively), and the state and the population disapprove of this process. However, experts acknowledge the fact that the use of informal practices in municipal management can lead to an acceleration of the administrative decision. However, in our opinion, the reproduction of the resources of the municipality cannot be distinguished in this category. The increase, accumulation and reproduction of the spent production, economic, organizational, social and other resources of the local community is one of the priority tasks of the municipal government, since with their lack, it becomes impossible both to develop and maintain the quality of life of the population at the required level. Those. informal practices of a positive nature should be aimed at increasing the level of provision of the local community with all the necessary resources, as well as increasing the efficiency of their use, i.e. obtaining the maximum effect while minimizing costs. In this regard, the opinion of municipal employees about what the municipal leader should rely on when making managerial decisions is interesting. The overwhelming majority of respondents noted that a leader should rely on modern methods and technologies specially designed for this: $45 \%$ completely agree with this statement and $44 \%$ "rather agree than disagree". It should also be noted that the officials indicated that it is necessary to involve various specialists in the discussion and adoption of important organizational decisions. More than half of the respondents $(66.7 \%)$ fully agreed with this point of view.

It should be noted that each of the second expert, noting the reasons for the negative effects of informal practices in the process of management decision-making at the municipal office, also pointed to the incompetence of some officials, taken under the protection $(46.7 \%)$. According to the expert survey, corruption of the municipal government also contributes to the spread of informal practices - so answered $26.7 \%$ of respondents. While the officials did not pay due attention to this reason, but, on the contrary, pointed out that informal practices contribute to effectively solving local issues. Perhaps this indicates the presence of insincerity in the answers of municipal employees. We believe that the revealed contradiction testifies not so much to a certain insincerity of the respondents, which undoubtedly takes place. The reasons are related to the specifics of ideas about the status of informal practices in society in general and in municipal officials in particular.

Appeal to the informal practices in their professional activities, have, according to their own opinion, the negative direction, municipal officials to explain the public interest (23.7\%). This desire is superimposed on the traditional for Russia some neglect law. An orientation not towards the law, but towards justice.

It is obvious that municipal employees use mainly the destructive potential of informal practices in their direct professional activities. At the same time, most likely, they consider such a situation as something natural, consecrated by tradition (it is no coincidence that only $20 \%$ of respondents from among the population considered the solution of personnel problems unacceptable, $33 \%$ indicated the pushing of interests).

According to the study, it can be concluded that today a stable tribal tradition with elements of nepotism has developed in the system of municipal government.

Thus, it should be noted that along with the pursuit of the realization of the group of interest among the causes of the spread of informal practices in terms of socio-economic development of rural areas are as follows.

1. Trying to make up for lack of resources, which is typical for most municipalities. In fact, life support of municipal territories turned depending on the size of informal flows of resources. This is where informal practices take on particular importance. For example, in the relations between the local government and business there agreement on the additional financing of territories by entrepreneurs. Entrepreneurs commitments for additional contributions to the development of local infrastructure are exchanged for the administration of the obligation to provide public order, access to the land lease of state property, and others.

2. Compensation for risks that arise as a result of general social instability in society. At the same time, it is significant that the formalization of activities often not only does not reduce, but also increases managerial risks, since it leads to an increase in the distance between the authorities and the population. As a result of its increase, in particular, it reduces the possibility of obtaining the accurate information needed to make appropriate decisions.

3. The intention to circumvent the imperfect rules and regulations that hold back the initiative. It should be noted that the legislation on local self-government is still imperfect, and 
not by chance is constantly changing. Some norms do not facilitate, but rather complicate the management process. In this case, informal practices compensate for imperfect norms. In fact, the life support of municipal territories turned out to depend on the scale of informal resource flows. Here informal practices are particularly important. For example, in the relations between the local government and business there agreement on the additional financing of territories by entrepreneurs. The obligations of entrepreneurs for additional deductions for the development of local infrastructure are exchanged for the obligations of the administration.

\section{CONCLUSION}

1. As a result of the study, a definition of the concept of "practice" is proposed as a stable, reproducible activity of actors aimed at transforming formal norms, performing compensating functions.

2. With regard to the system of municipal government in terms of socio-economic development of rural areas informal practices act intuitively shaped patterns of behavior in the exercise of administrative head of the action for the implementation of alternative choices based not on scientific validity and adherence to the strategic guidelines of development of the municipality, and to their own private interests persons.

Technologies for the constructive use of informal practices in municipal governance should be based on a seriously developed scientific and methodological base due to the high degree of responsibility of territorial authorities to the local community. The primary should be a matter of assessing the potential of various informal practices in local government of different spheres and levels. We defined the criteria will determine the constructive and destructive practices evaluated, but it is also necessary to focus on the specifics of a particular municipality, especially managerial decisionmaking in them and formed in the process of development of the municipal tradition of management. On the basis of what will be possible to determine the most destructive practices applied in a municipality, and potentially effective practice with their meaningful use.

\section{ACKNOWLEDGMENT}

The study was carried out within the framework of the state assignment of the National Research University "BelSU" for 2020, project No. 0624-2020-0027 "Socio-demographic determinants of the development of rural areas of the Central Black Earth Economic Region".

\section{REFERENCES}

[1] M. Weber, "History of the Economy: City", KANONPress, 2001

[2] I.V. Vydrin, "New Trends in the Territorial Organization of Local Self-Government", Russian Justice, 5 (2012) 11-14. URL: https://www.elibrary.ru/item.asp?id= 17726149.

[3] V.A. Yasyunas, "Local government: comments". Explanations, OS'-89, 1997.

[4] A.E. Kogut, V.A. Gnevko, "Local Self-Government in Russia: Foundations of a Systems Approach, Institute of Socio-Economic Problems RAS, Institute of Management and Economics", 1997. URL: https: //rusneb.ru/catalog/000219 000026 RU \%D0\%93\%D $0 \% 9 \mathrm{~F} \% \mathrm{D} 0 \% 9 \mathrm{D} \% \mathrm{D} 0 \%$ A $2 \%$ D0\% $91+\%$ D0\% A0\%

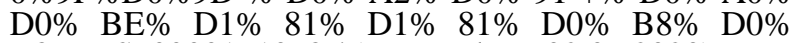
B8 IBIS 0000171078 / (accessed on: 02.09.2020).

[5] G.V. Atamanchuk, "Management in the life of people". Essays on Problems, RAGS Publishing House, 2008.
[6] V.N. Ivanov and V.I. Patrushev, "Innovative social technologies of state and municipal government", Economics, 2001

[7] N.I. Lapin, "How they feel, what are the citizens of Russia striving for, Sociological research". 6 (2003) 78-87. URL: http: //ecsocman.hse.ru/data/623/191/1217/011Lapin_N.I.pdf (accessed on: 02.09.2020).

[8] T.G. Golubeva, "Transformation of theoretical and practical approaches to the formation of the institution of local self-government in Russia" (historical and political aspect): monograph, SKAGS, 2010.

[9] P. Bourdieu, "Sociology of Politics", Thought, 1993.

[10] N. Fligstein, "The Spread of the Multidivisional Form among Large Firms", 1919-1979, American Sociological Review. 3 (1985) 377-391. doi: 10.2307 / 2095547 (accessed on: 02.09.2020).

[11] P. Berger, T. Luckmann, "Social construction of reality. A Treatise on the Sociology of Knowledge", Medium, 1995.

[12] A.B. Daugavet, "Informal Practices of the Russian Elite" (Approbation of the Cognitive Approach), Polis. 4 (2003) 26-38. doi: 10.17976 / jpps / 2003.04.03

[13] J.T. Toshchenko, "Elite? Clans? Castes? Clicks? What should we call those who rule us?" Socis. 11 (1999) 123133 URL: http: //ecsocman.hse.ru/data/000/ 094/1217/020_Sotsiologicheskaya_publitsistika.pdf (accessed on: 02.09.2020).

[14] A.K. Magomedov, M.M. Kirichenko, "From Yeltsin to Putin: The Kremlin and Regional Russia (on the Example of the Ulyanovsk Region and Krasnodar Territory), The Phenomenon of Vladimir Putin and the Russian Regions: An Unexpected or Natural Victory?", Moscow-Sapporo: Slavic Research Center Hokkaido University, 2004. URL: http: //srch.slav.hokudai.ac.jp/coe21/publish/no1_ses/statia5.pdf (accessed on: 02.09.2020).

[15] S.S. Sulakshin, S.V. Maksimov, I.R. Akhmetzyanova, "State policy of combating corruption and the shadow economy in Russia": monograph, Scientific expert, 2009.

[16] A.V. Ponedelkov, "Political Elite: Genesis and Problems of Its Formation in Russia", Rostov-on-Don: SKNTs VSh, 1995

[17] L. Ya. Dyatchenko, V.P. Babintsev "Formation of sociotechnological culture as a theoretical and praxeological problem", Sociological research. 7 (2011). 65-70. URL: http://dspace.bsu.edu.ru/bitstream/123456789/3727/1/D yatchenko\%20L.Ya._Formirov.pdf (accessed on: 02.09.2020).

[18] R.I. Sarik, "Innovative management approaches as the basis for improving organizational relations in local government", Bulletin of State and Municipal Management. 2 (2013) 244-252. URL: https: //cyberleninka.ru/article/n/innovatsionnyeupravlencheskie-podhody-kak-osnovasovershenstvovaniya-organizatsionnyh-otnosheniy-vmestnom-samoupravlenii (accessed on: 02.09.2020).

[19] Z. Bauman, "Individualized Society", Logos, 2005.

[20] M. Weber, "Selected Works", Progress, 1990.

[21] D. North, "Institutions, Institutional Change and Economic Performance, Foundation for the Economic Book "Beginnings", 1997.

[22] G. Helmke, S. Levitsky, "Informal Institutions and Comparative Politics": A Research Agenda, Perspectives on Politics. 2 (4) (2004) 725-740. URL: http: //rochelleterman.com/ComparativeExam/sites/default/fi les/Bibliography\%20and\%20Summaries/Helmke\%20an d\%20Levitsky\%202004.pdf (accessed on: 02.09.2020).

[23] T. Parsons, "On the Structure of Social Action", Academic Project, 2000.

[24] E. Durkheim, "Sociology. Its subject, method, purpose, Canon", 1995.

[25] R. Merton, "Social Theory and Social Structure", AST, Guardian, 2006

[26] I.A. Gromov, A. Yu. Matskevich, "Western theoretical sociology: E. Giddens' theory of structurization", Olga, 1996

[27] V.I. Dyatlov, "Migrants and Diasporas in Eastern Russia: Practices of Interaction with Society and State", Natalis, 2007. 
[28] A.S. Gottlieb, "An Introduction to Social Research. Qualitative and quantitative approaches. Methodology". Research Practices, FLINT, 2014.

[29] V.A. Lapin, "The Nature of Municipal Power and Local Self-Government in Russia, Personality. Culture. Society". 2 (1) (2000) 42-52. URL: https: //www.elibrary.ru/item.asp? Id $=9158178$ (accessed on: 02.09.2020).

[30] M. Hannan, J. "Freeman, Organizational Ecology", Cambridge, Harvard University Press, 1989.

[31] K. Polanyi, "The Great Transformation. Political and Economic Origins of Our Time", Aletheia, 2002.

[32] V.V. Radaev, Sociology of Markets: "Towards Formation of a New Direction", State University, Higher School of Economics, 2003.

[33] R. Merton, "Explicit and Latent Functions", DirectMedia, 2007.

[34] G. Besker "Investment in Human Capital: A Theoretical Analysis, of Political Economy". 70 (5) (1990) 9-49. doi: $10.1086 / 258724$. 